Article

\title{
Virtual Synchronous Motor Based-Control of a Three-Phase Electric Vehicle Off-Board Charger for Providing Fast-Charging Service
}

\author{
Xiangwu Yan ${ }^{1, *}$, Jiajia Li ${ }^{1}$, Bo Zhang ${ }^{1}$, Zhonghao Jia ${ }^{1}$, Yang Tian ${ }^{1}$, Hui Zeng ${ }^{2}$ and Zhipeng Lv $^{3}$ \\ 1 Key Laboratory of Distributed Energy Storage and Micro-Grid of Hebei Province, \\ North China Electric Power University, Baoding 071003, China; lijiajia1018@163.com (J.L.); \\ zhangbo@ncepu.edu.cn (B.Z.); 15032233997@163.com (Z.J.); yangyunxiahui@163.com (Y.T.) \\ 2 Electric Power Research Institute of State Grid Liaoning Electric Power Co. Ltd., Shenyang 110006, China; \\ m18609836798@163.com \\ 3 China Electric Power Research Institute (CEPRI), Beijing 100192, China; lvzhipeng@epri.sgcc.com.cn \\ * Correspondence: xiangwuy@ncepu.edu.cn
}

Received: 11 April 2018; Accepted: 18 May 2018; Published: 23 May 2018

\begin{abstract}
This study introduces a three-phase virtual synchronous motor (VSM) control and its possible application for providing fast-charging service from off-board chargers of electric vehicles (EVs). The main circuit of the off-board charger consists of a three-phase voltage source PWM rectifier (VSR) and a resonant LLC zero-voltage-switching converter. In the proposed control approach, VSM-controlled pre-stage VSR emulates the external characteristics of a synchronous motor (SM), simultaneously, droop control based on charging mode in the VSM can satisfy the demand of the EVs constant-current fast-charging; The post-stage DC-DC converter is responsible for stabilizing the DC bus voltage. The feature of this control strategy is that VSM and fast charging control are implemented by the pre-stage converter, which has better coordination. In the MATLAB, the equivalent synchronous grid of the distribution network supplies to the power battery through the off-board charger, and the effectiveness of the presented control is demonstrated by typical working conditions.
\end{abstract}

Keywords: electric vehicle; virtual synchronous motor; frequency and voltage regulation; off-board charger; fast charging; equivalent synchronous grid

\section{Introduction}

The energy crisis [1] and environmental pollution [2] are the main reasons for leveraging the large-scale adoption of electric vehicles (EVs). The Chinese government has energetically supported the EV's establishment. In April 2012, the 'Energy Conservation and New Energy Vehicle Industry Development Plan (2012-2020)' formulated by the State Council pointed out that "in 2020, pure electric vehicles and plug-in-hybrid electric vehicles will be industrialized, and their cumulative production and sales will exceed 5 million." The rapid growth of EVs has increased their permeability in the distribution network.

The charging mode of EVs is mainly divided into slow charging [3] and fast charging [4]. Slow charging is appropriate for low-power on-board chargers [5], the charging time of which is customarily in excess of $6 \mathrm{~h}$. On the contrary, fast charging is generally utilized to high-power off-board chargers, which is an attractive option over slow charging due to its potential to fully charge the EV in less than $1 \mathrm{~h} \mathrm{[6].} \mathrm{Thus,} \mathrm{fast} \mathrm{charging} \mathrm{is} \mathrm{favored} \mathrm{by} \mathrm{consumers} \mathrm{thanks} \mathrm{to} \mathrm{economize} \mathrm{on} \mathrm{time} \mathrm{[7].}$

However, for the power system, EVs are nonlinear loads whose frequent input and exit will provoke a negative impact on the power quality of the distribution network [8-10]. To alleviate the 
above problems, loads-virtual synchronous motor (VSM) technology has attracted more attention due to its ability to improve stability of frequency and voltage. On account of this superiority, some scholars put forward the application of VSM to the EV chargers [11-14]. Indeed, VSM can provide inertia and damping to suppress rapid changes in voltage and frequency during transients. Furthermore, EVs autonomously participate in the primary regulation to achieve responsive interaction with the grid in the steady case.

As a promising control approach, the VSM has been intensively investigated since it can resolve the EVs integration problems most flexibly. The provision of ancillary services from VSM-controlled single-phase chargers has previously been discussed [11,12]. However, with widespread concern of fast charging, VSM-based control has gradually concentrated on three-phase power converters. If a VSM implementation designed for single-phase systems is directly applied to a three-phase converter, the control structure will be further complicated. Aiming at the three-phase EV charger composed of two-stage topology, the VSM construction method is distinct with sing-stage VSC in [12], which can take graded-control in the pre-stage AC/DC and post-stage DC/DC in accordance with its control objective [13]. In addition, if three-phase VSM continue to employ proportional resonant (PR) controller which is used in single-phase control, this implies that six PR controllers will be needed for achieving double closed-loop control. Nevertheless, this can be avoided by leading into vector control based on three-phase instantaneous reactive power theory, as mentioned in $[13,14]$.

The proposal for actualizing three-phase VSM has been proposed in [13]. On this basis, [14] extends to VSM control based on fast charging mode, in which the pre-stage converter implements VSM function and maintains the DC bus voltage stability, and the post-stage circuit realizes constant-voltage charging by means of double closed-loop control. However, since resistance is leveraged for emulating the power battery, the charging mode is not clear, which can be considered as constant-voltage charging due to invariance of resistance voltage. But fast charging adopts constant-current/power mode in general. Additionally, simulation results can be incapable of reflecting the primary frequency regulation characteristic of VSM owing to the application of ideal power grid model.

Thus, in view of the deficiencies in [14], following the graded-control thought and the vector control based on three-phase instantaneous reactive power theory $[13,14]$, this paper presents a novel VSM control scheme suitable for the fast charging of the off-board chargers. VSM-controlled pre-stage PWM rectifier is provided with inertia, damping and primary regulation capabilities. Importantly, in the VSM strategy, droop control based on charging mode allows off-board charger to operate with constant-current fast charging. The post-stage LLC converter contributes to the stability of the DC bus voltage. The control targets of the two stage circuits are different and the division of labor is clear. Using equivalent synchronous gird can validate the primary regulation behaviors of VSM and the actual dynamic features of the distribution network. The intended performance of the proposed method and the system was verified through simulation.

\section{Overview of System Configuration}

For the investigated case, the main circuit of the off-board charger comprised of a full-bridge resonant LLC converter and a three-phase voltage source PWM rectifier is interfaced with the synchronous grid through LC filter, as indicated in Figure 1.

The fast charger control strategy is split into two major parts, which are the pre-stage VSM control and post-stage double closed-loop control.

- VSM control not only ensures inertia and damping emulation and frequency support as well as voltage control, but also make the off-board charger provide the constant-current fast charging service for the EV's power battery.

- Double closed-loop control is in charge of stabilizing the DC bus voltage $U_{\mathrm{dc}}$.

Figure 1 only shows an overview of the overall control scheme, so the implementation of these control functions is described in detail in the following sections. 


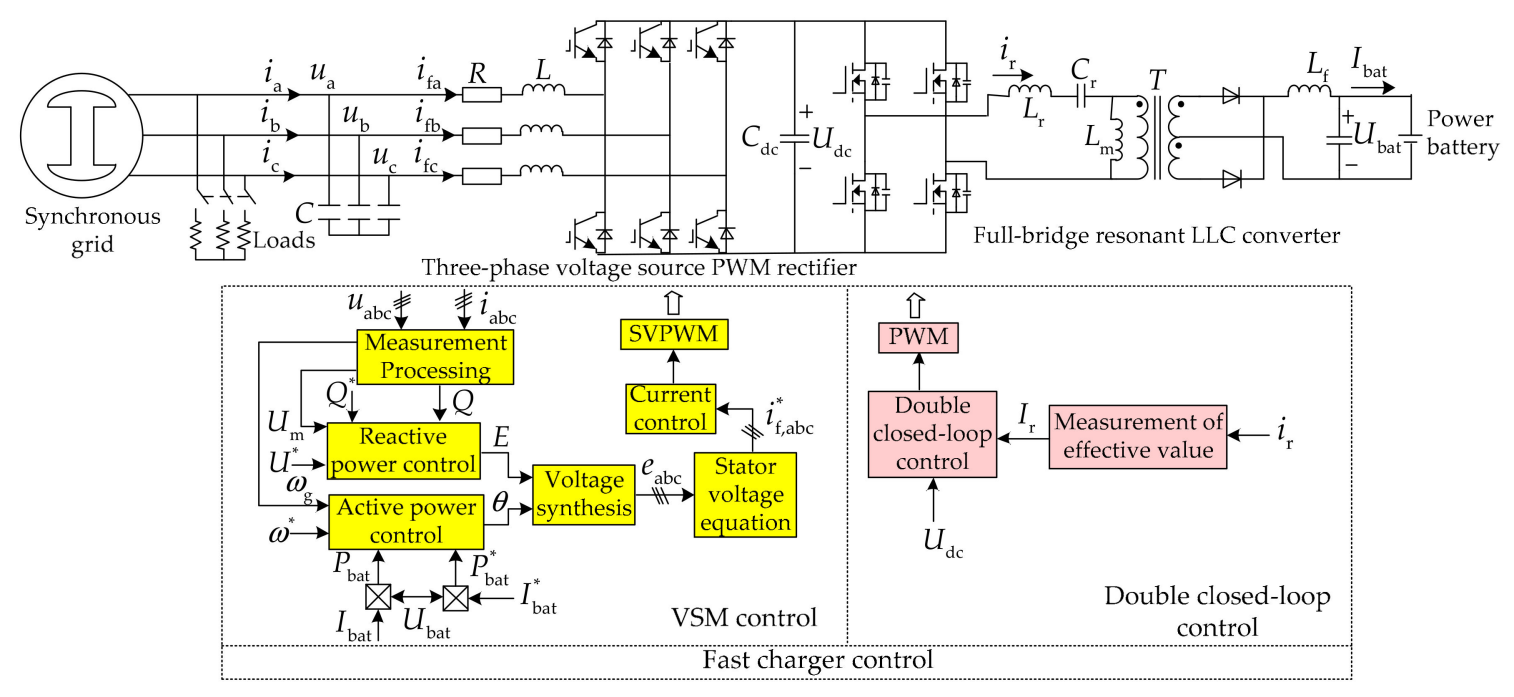

Figure 1. The main circuit topology and fast charger control strategy.

\section{Off-board Charger Control}

\subsection{VSM Control}

In this section, an elaborate effectuation of the presented VSM, including power-frequency controller, excitation regulator, stator voltage equation and inner-loop current controller, is shown in Figure 2. Subsequent subsections will address how to derive such VSM control.

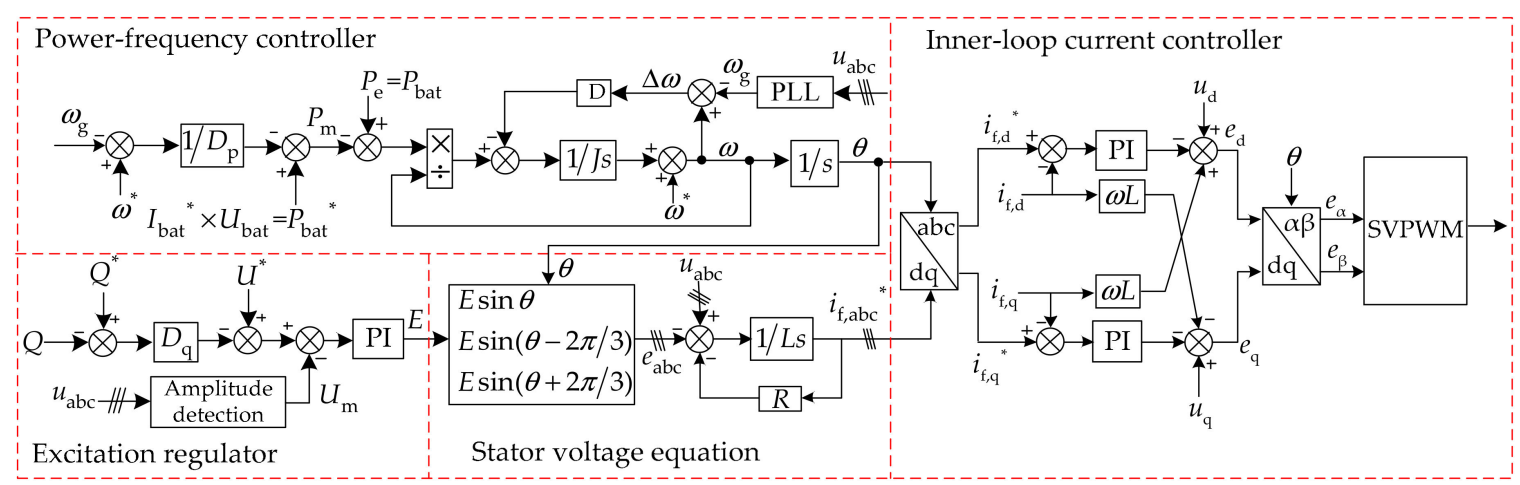

Figure 2. Applied control structure of virtual synchronous motor (VSM).

\subsubsection{Droop Control Based on Charging Mode}

Primary frequency/voltage regulation is a fundamental feature of the VSM control. In previous related studies [15,16], the active power $P$ and reactive power $Q$ of the rectifier are leveraged to achieve the droop control, and the $P-\omega$ and $Q-U$ curves is shown in Figure 3a. The above-mentioned commonly-used droop control only incarnates the primary regulation characteristics of VSM, but it cannot bring about the proposed fast charging function. Thus, in order to accomplish the above goal, this paper presents the droop control based on charging mode, whose $P_{\text {bat }}-\omega$ and $Q-U$ curves is expressed in Figure $3 b$, in which $Q-U$ curve remains invariable while the charging power $P_{\text {bat }}$ substitutes the active power of the rectifier $P$. 

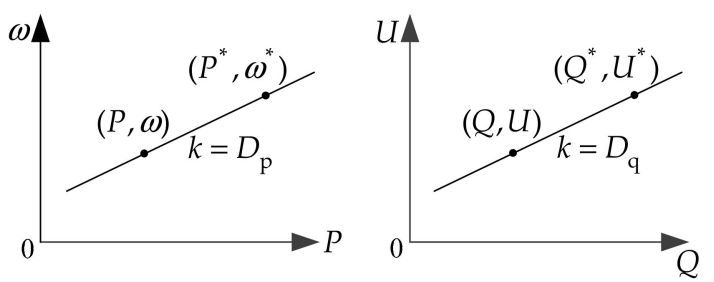

(a)
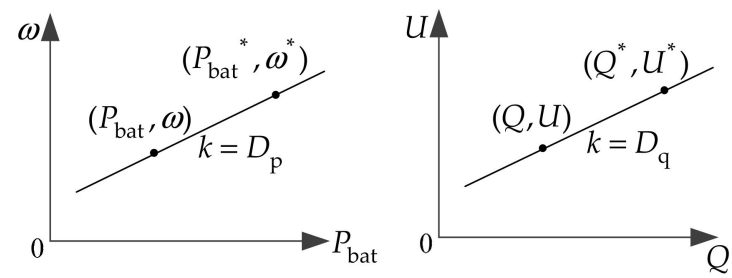

(b)

Figure 3. Comparison chart of the droop curves (a) Traditional droop curves; (b) Droop curves based on charging mode.

$P$ and $P_{\text {bat }}$ represent the active power of the rectifier and charging power of the power battery, respectively. $\omega$ is the angular frequency. $Q$ and $U$ are the reactive power and the AC voltage amplitude of the rectifier. $D_{\mathrm{p}}$ and $D_{\mathrm{q}}$ are the frequency and voltage droop coefficients. Reference values for any given signal $\mathrm{x}$ are indicated by a superscript asterisk as $\mathrm{x}^{*}$.

According to the droop curves based on the charging mode in Figure 3b, the droop relations of the $P_{\text {bat }}-\omega$ and $Q-U$ are given by

$$
\begin{gathered}
D_{\mathrm{p}}=\frac{\omega^{*}-\omega}{P_{\text {bat }}{ }^{*}-P_{\text {bat }}} \quad\left(D_{\mathrm{p}}>0\right) \\
D_{\mathrm{q}}=\frac{U^{*}-U}{Q^{*}-Q} \quad\left(D_{\mathrm{q}}>0\right)
\end{gathered}
$$

Equations (1) and (2) are transformed to

$$
\begin{gathered}
\omega=\omega^{*}-D_{\mathrm{p}}\left(P_{\text {bat }}{ }^{*}-P_{\text {bat }}\right) \quad\left(D_{\mathrm{p}}>0\right) \\
U=U^{*}-D_{\mathrm{q}}\left(Q^{*}-Q\right) \quad\left(D_{\mathrm{q}}>0\right)
\end{gathered}
$$

To integrate with the constant-current charging, we alter the setting form of $P_{\mathrm{bat}}$ * in Equation (3), as shown in Equation (5).

$$
P_{\text {bat }}^{*}=U_{\text {bat }} \times I_{\text {bat }}{ }^{*}
$$

Battery Model is adopted in the system. $U_{\text {bat }}$ is the feedback value of the real-time charging voltage of Battery, which changes with variation of state of charge (SOC) and charging current during the charging process. $I_{\text {bat }}{ }^{*}$ is the charging current reference value. The product of $U_{\text {bat }}$ and $I_{\text {bat }}{ }^{*}$ constitutes the charging power reference $P_{\text {bat }}{ }^{*}$.

Since the unit of the battery capacity is $\mathrm{Ah}$, which is the product of Charging current (A) and Time $($ h), i.e., Capacity $(\mathrm{Ah})=$ Charging current $(\mathrm{A}) \times$ Time $(\mathrm{h})$, Charging current $(\mathrm{A})$ is equal to the quotient of Capacity (Ah) and Time (h), i.e., Charging current (A) = Capacity (Ah)/Time (h). The fast charging time is usually less than an hour, i.e., Time $(\mathrm{h})<1 \mathrm{~h}$, so if the constant-current fast charging intends to be fulfilled, we should assign that the set value of the charging current $I_{\text {bat }}{ }^{*}$ is greater than the value of the power battery capacity, i.e., $I_{\text {bat }}^{*}>\mid$ Capacity $(\mathrm{Ah}) \mid$. 
Thus, in accordance with the above analysis, the active droop relation combined with constant-current fast charging is obtained in Equation (6).

$$
\omega=\omega^{*}-D_{\mathrm{p}}\left(I_{\text {bat }}^{*} \times U_{\text {bat }}-P_{\text {bat }}\right)\left(D_{\mathrm{p}}>0\right)
$$

The actual angular frequency is acquired through a PLL measurement in engineering control, so $\omega$ is expressed by $\omega_{\mathrm{g}}$. Integrating the relationships of Equation (4), Equation (6) and $\omega_{\mathrm{g}}$, the new primary regulation features of the proposed VSM are shown by Equation (7).

$$
\left\{\begin{array}{l}
\omega_{\mathrm{g}}=\omega^{*}-D_{\mathrm{p}}\left(I_{\mathrm{bat}}{ }^{*} \times U_{\mathrm{bat}}-P_{\mathrm{bat}}\right) \\
U=U^{*}-D_{\mathrm{q}}\left(Q^{*}-Q\right)
\end{array}\right.
$$

In conclusion, in the presented three-phase VSM, the droop control based on charging mode possesses two major contributions:

- The rectifier is the capacity to take part in the primary regulation of the voltage and frequency in the case of steady state.

- The off-board charger feeds the power battery in the way of constant-current fast charging.

\subsubsection{Behaviors of the Inertia and Damping}

Another core objective of the VSM is to enable the rectifier externally exhibit the inertia and damping of the SM, which is generally indicated by a simplified classic second-order model of an SM. The VSM rotor equation of motion can be described by the equation below.

$$
\left\{\begin{array}{l}
J \frac{\mathrm{d}\left(\omega-\omega^{*}\right)}{\mathrm{d} t}=\frac{P_{\mathrm{e}}-P_{\mathrm{m}}}{\omega}-D\left(\omega-\omega_{\mathrm{g}}\right) \\
\frac{\mathrm{d} \theta}{\mathrm{d} t}=\omega
\end{array}\right.
$$

where: the inertia is given by J; $D$ represents the damping coefficient; $P_{\mathrm{e}}$ is the electromagnetic power; $P_{\mathrm{m}}$ is mechanical power; $\omega$ is electrical angular velocity of the VSM; $\omega^{*}$ is the rated angular frequency; $\omega_{\mathrm{g}}$ is the grid angular frequency; $\theta$ is the power angle.

In order to connect the inertia and damping of the VSM (Equation (8)) with $P_{\text {bat }}-\omega$ droop control (Equation (7)) to comprise a power-frequency controller, there are two setting forms depending on whether losses are considered. If the efficiency of the conversion circuit is extremely high, the losses can be ignored. The relations are defined by Equation (9).

$$
\left\{\begin{array}{l}
P_{\mathrm{m}}=I_{\mathrm{bat}}{ }^{*} \times U_{\mathrm{bat}}-\left(\omega^{*}-\omega_{\mathrm{g}}\right) / D_{\mathrm{p}} \\
P_{\mathrm{e}}=P_{\mathrm{bat}}
\end{array}\right.
$$

If the efficiency is not neglected, assuming that we continue to use Equation (9), which will make the actual charging current slightly less than the set value, i.e., $I_{\text {bat }}<I_{\text {bat }}{ }^{*}$. Thus, to strictly let $I_{\text {bat }}=$ $I_{\text {bat }}{ }^{*}$, Equation (9) is amended as follows.

$$
\left\{\begin{array}{l}
P_{\mathrm{m}}=\frac{1}{\eta} \times\left(I_{\mathrm{bat}} * \times U_{\mathrm{bat}}-\left(\omega^{*}-\omega_{\mathrm{g}}\right) / D_{\mathrm{p}}\right) \\
P_{\mathrm{e}}=P_{\mathrm{bat}}
\end{array}\right.
$$

In the Equation (10), $\eta$ is the efficiency coefficient which varies with power, whose expression is $\eta=P_{\text {bat }} / P . P$ is not only the rectifier power but also the input power of the off-board charger. $P_{\text {bat }}$ represents the charging power of the power battery as well as the output power of the off-board charger.

Equations (9) and (10) signify that the mechanical power $P_{\mathrm{m}}$ is represented by the $P_{\mathrm{bat}}-\omega$ droop control, and the electromagnetic power $P_{\mathrm{e}}$ is denoted by real-time charging power $P_{\text {bat }}$ of the power battery. 
In addition to the power-frequency controller, Figure 3 also includes the excitation regulator and the stator voltage equation. The excitation regulator contains a closed-loop control between the $Q-U$ droop (Equation (4)) and the AC voltage amplitude $U_{\mathrm{m}}$ of the rectifier. Electrical angle $\theta$ of the power controller and $E$ of the excitation regulator synthesize the three-phase excitation electromotive force $e_{\mathrm{abc}}$ through Equation (11).

$$
e_{\mathrm{abc}}=\left[\begin{array}{c}
E \sin \theta \\
E \sin (\theta-2 \pi / 3) \\
E \sin (\theta+2 \pi / 3)
\end{array}\right]
$$

To enhance the stability and waveform quality of the VSM-based control system, the power outer-loop composed of the power-frequency controller and the excitation regulator requires to be combined with the inner-loop current controller by the stator voltage equation, which is illustrated by

$$
u_{\mathrm{abc}}=e_{\mathrm{abc}}+R i_{\mathrm{abc}}+L \frac{d i_{\mathrm{abc}}}{d t}
$$

The inductor $L$ and resistance $R$ in the LC filter are invoked as the synchronous reactance and armature resistance of the stator electrical equation. The inner-loop current controller provides the modulation index for SPVWM which generates the pulse signals of the rectifier switching transistor. Thus, the studied VSM can support the virtual inertia and damping for the grid during transient operation.

\subsection{Double Closed-Loop Control}

The DC/DC converter in the off-board charger uses a full-bridge resonant LLC converter that is frequently used in practical applications. This converter not only actualizes the electrical isolation between the power battery and the grid, but also has the characteristics of high power transmission and high efficiency, which can meet the fast charging requirement of high-capacity electric vehicles $[17,18]$. The double closed-loop control which is shown in Figure 4 will be mainly relevant for ensuring the stability of the DC bus voltage $U_{\mathrm{dc}}$. The post-stage DC/DC converter does not directly regulate the charging power $P_{\text {bat }}$ of the power battery, which is processed by pre-stage AC/DC converter.

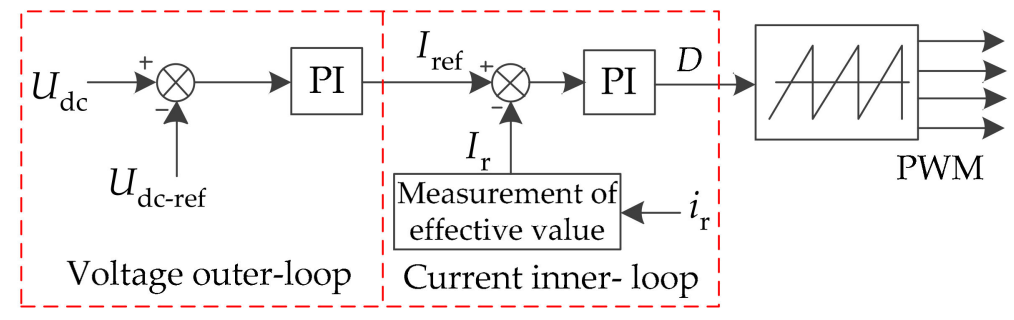

Figure 4. Double closed-loop control.

It can be noticed from Figure 4 that the inner-loop current reference value $I_{\text {ref }}$ which is obtained by outer-loop voltage $U_{\mathrm{dc}}$ control and the effective value $I_{\mathrm{r}}$ of resonant current emit the PWM modulated signals $D$ through PI control. When the battery is charged, the full-bridge resonant LLC converter is in the step-down mode. Under such circumstances, the direction of the current flowing into the battery is positive, i.e., $I_{\mathrm{bat}}>0$, but $U_{\mathrm{dc}-\mathrm{ref}}-U_{\mathrm{dc}}<0$. Accordingly, the reference value of the inner-loop current is engendered by using $U_{\mathrm{dc}}-U_{\mathrm{dc}-\text { ref }}$ for PI control.

\section{Synchronous Grid Control}

In past related studies on the EV system connected into the power grid, the ideal grid model was widely used. In this case, the grid frequency keeps constant no matter how the loads changed. Since the impact of frequent input and exit of high-power charging loads on the grid frequency is planned 
to be examined, the ideal grid model is unsuitable for the research purpose. Thus, the equivalent synchronous grid model has been designed and shown in Figure 5. For this model, the equivalent synchronous grid constituted of the synchronous generator (SG) with primary regulation characteristics is the equivalent simulation of all the power supplies in the practical grid, whose capacity is equal to the sum of the capacities of all the power supplies.

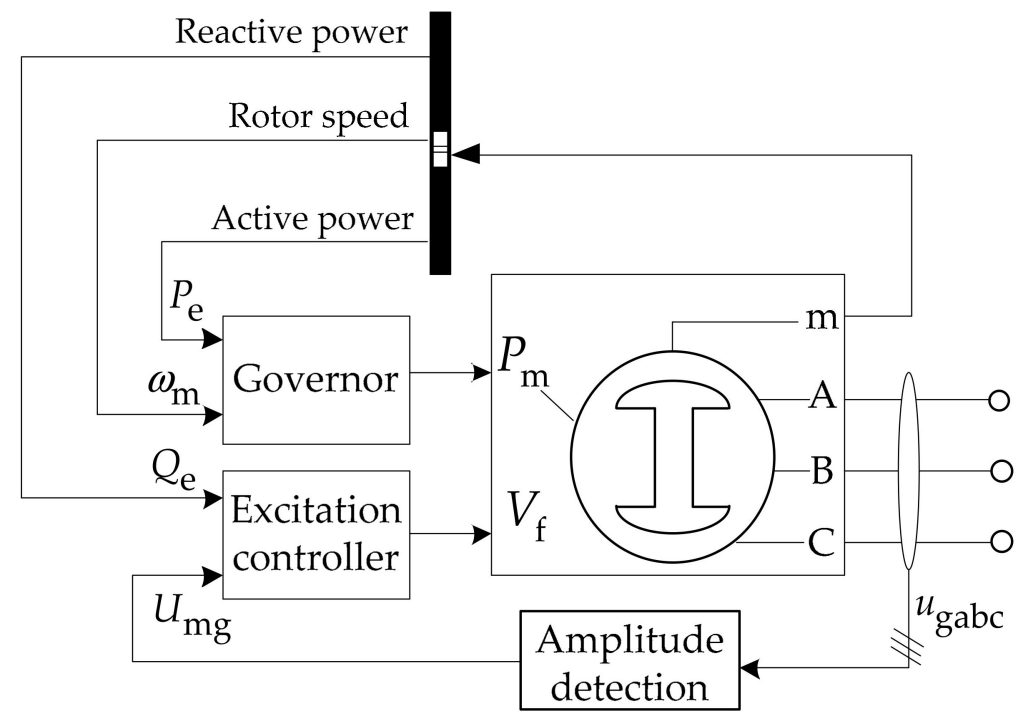

Figure 5. The synchronous grid model.

Governor and excitation controller of the synchronous grid are designed according to the droop curves of the power generation, which can be seen in Figure 6. In the following control, $P_{\mathrm{e}}, Q_{\mathrm{e}}$ and $\omega_{\mathrm{m}}$ are output active power, output reactive power and rotor speed of the SG respectively. $D_{\mathrm{pg}}$ and $D_{\mathrm{qg}}$ are the droop coefficients of the synchronous grid. $U_{\mathrm{mg}}$ is the SG actual output voltage $u_{\mathrm{gabc}}$ amplitude.

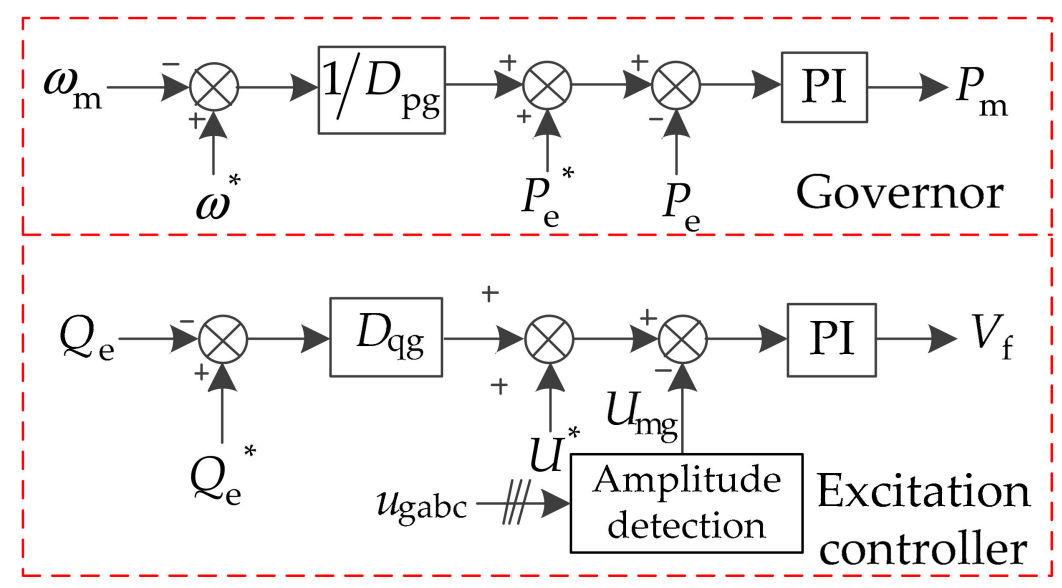

Figure 6. Control strategy of the synchronous grid.

In short, the synchronous grid not only displays the impact on frequency variations in the power system, but also is conductive to validate the primary frequency regulation characteristic of the VSM. Therefore, the synchronous grid is employed to emulate the actual distribution network, for ease of reading, which is abbreviated as the grid in the subsequent sections. 


\section{Verification}

In this section, the basic functionalities of the proposed VSM and fast-charging ability of the off-board charger are investigated. First, the overall system model described in Figure 7 is established in MATLAB/Simulink. Then, contrasted with the traditional control scheme of the EV, the performance of the proposed control is validated.

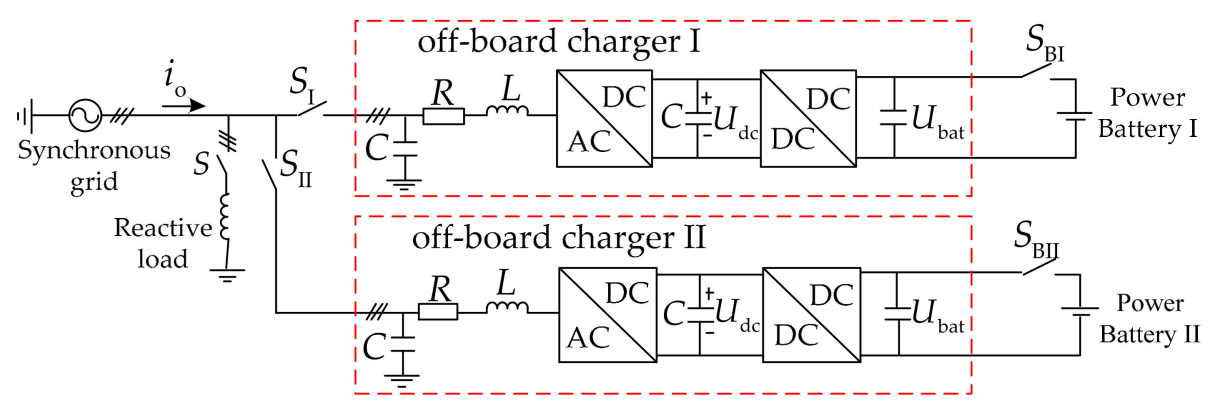

Figure 7. Simulation model structure diagram.

\subsection{Simulation Parameters}

The main components parameters of the investigated system are reported in Table 1.

Table 1. Simulation parameters.

\begin{tabular}{llc}
\hline & \multicolumn{1}{c}{ Parameters } & Values \\
\hline \multirow{3}{*}{ Filter parameters } & The series inductance of the filter, $L$ & $3 \mathrm{mH}$ \\
& The series resistance of the filter, $R$ & $0.5 \Omega$ \\
& The parallel capacitance of the filter, $C$ & $10 \mu \mathrm{F}$ \\
\hline \multirow{5}{*}{ LLC converter parameters } & DC side capacitance, $C$ & $1900 \mu \mathrm{F}$ \\
& Resonant inductor, $L_{\mathrm{r}}$ & $0.06 \mathrm{nF}$ \\
& Resonant capacitor, $C_{\mathrm{r}}$ & $34 \mu \mathrm{F}$ \\
& Excitation inductance, $L_{\mathrm{m}}$ & $0.24 \mathrm{nH}$ \\
& Transformer ratio, $T$ & 1.4 \\
\hline \multirow{2}{*}{ Power battery parameters } & Nominal voltage & $400 \mathrm{~V}$ \\
& Rated capacity & $100 \mathrm{Ah}$ \\
\hline \multirow{3}{*}{ System parameters } & Reference value of DC voltage, $U_{\mathrm{dc}-\text { ref }}$ & $800 \mathrm{~V}$ \\
& Resonant frequency & $35 \mathrm{kHz}$ \\
& Rated frequency & $50 \mathrm{~Hz}$ \\
& AC phase voltage effective value & $220 \mathrm{~V}$ \\
& Rectifier switching frequency & $10 \mathrm{kHz}$ \\
\hline
\end{tabular}

The integrated system model of the power battery connected to the synchronous grid by off-board chargers is built on the MATLAB/Simulink, as shown in Figure 7.

The synchronous grid adopts the control model presented in Figure 5 of Section 4. AC/DC and DC/DC converters are three-phase voltage source PWM rectifier and the full-bridge resonant LLC converter in Section 2, respectively. The power battery I/II are the Nickel-Metal Hydride battery.

\subsection{Verification Process}

\subsubsection{Verification of the Basic Functionalities of the Proposed VSM Control}

For VSM-controlled off-board charger system, its inertia and damping characteristics as well as primary regulation abilities are required to be proved, whose validation results are in the following subsections. 
(1) Verification of the Inertia and Damping Characteristics

Taking the off-board charger I as an example in Figure 7, three typical values of the inertia and damping are selected separately to observe the effects of different inertia and damping on the active power of the rectifier, which are $J=0.05,1,1.5$ and $D=12,20,30$, respectively. In the initial state, the grid sends power to the power battery I and the power battery II. Power battery II is out of service at $1 \mathrm{~s}$. Figure 8 shows the waveforms of the rectifier's active power varying with the inertia $J$ and the damping $D$.

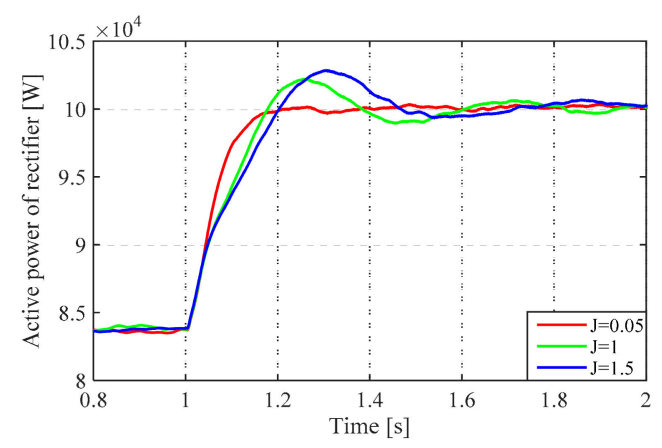

(a)

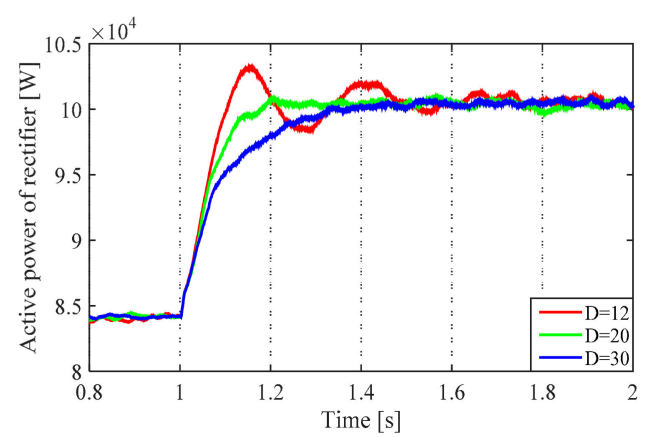

(b)

Figure 8. The influence of different inertia and damping on the active power of the rectifier (a) Different inertia J; (b) Different damping D.

First, it is evident from Figure 8 that the proposed VSM introduces the inertia and damping characteristics of the synchronous motor into the control of the off-board charger in the transient process. Next, active power of the rectifier increases $8.4 \mathrm{~kW}$ to $10 \mathrm{~kW}$ due to the abrupt exit of the power battery II. For inertia, it can be observed from Figure $8 \mathrm{a}$ that it can restrain the sudden power change, but with the increase of inertia, dynamic response of the system slows down. Moreover, compared with $J=0.05$, the active power starts to oscillate when $J=1$, and oscillation amplitude of $J=1.5$ is greater than $J=1$. For damping, it can be noticed in Figure $8 \mathrm{~b}$ that damping suppresses oscillations, where oscillation amplitude decrease in order with the increase of damping $D$, but overdamping will make the system take longer to reach steady state. Therefore, the abovementioned inertia and damping effects are consistent with the dynamic characteristics of the synchronous motor, and choosing the appropriate inertia and damping is of great significance to enhance the stability of the charging system.

\section{(2) Verification of Primary Regulation}

Similarly, regarding the off-board charger I in Figure 7 as a focus point, we verify the primary regulation of VSM whose simulation results are depicted in Figure 9. The simulation scenario is set as follows:

(1) Before $1.5 \mathrm{~s}$, the power grid supplies power to $1 \mathrm{kVar}$ reactive load, power battery I and power battery II.

(2) Off-board charger II is out of operation at $1.5 \mathrm{~s}$ and connects to the power grid again at $2.5 \mathrm{~s}$.

(3) $1 \mathrm{kVar}$ reactive load at the AC interface exits operation at $3.5 \mathrm{~s}$.

It is worth noting that when the active power and reactive power fluctuates, the adjustment ratio of the grid and off-board charger I is set to 1:1. In addition, the active power of the off-board charger II is set to $30 \mathrm{~kW}$.

From Figure 9a,c, according to the 1:1 adjustment ratio, except the power undertaken by the grid, the rectifier increases the absorption of $15 \mathrm{~kW}$ active power between 1.5 and $2.5 \mathrm{~s}$, and the reactive power of rectifier changes from -500 Var to 0 Var due to the withdraw of the reactive load at $3.5 \mathrm{~s}$. 
Meanwhile, we can see from Figure 9b,d that the frequency and voltage of the VSM are adjusted according to their droop characteristics. Therefore, in the steady state, the proposed VSM participates in the regulation of frequency and voltage when the charging load is frequently input and exit.

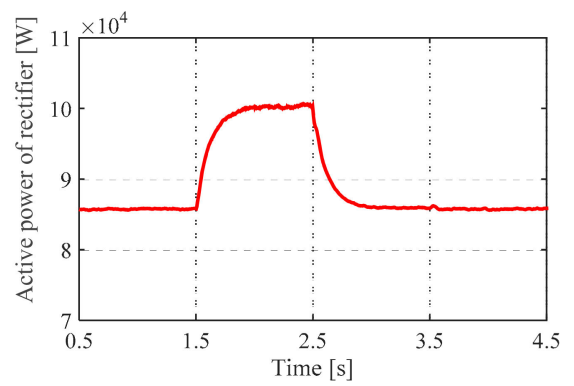

(a)

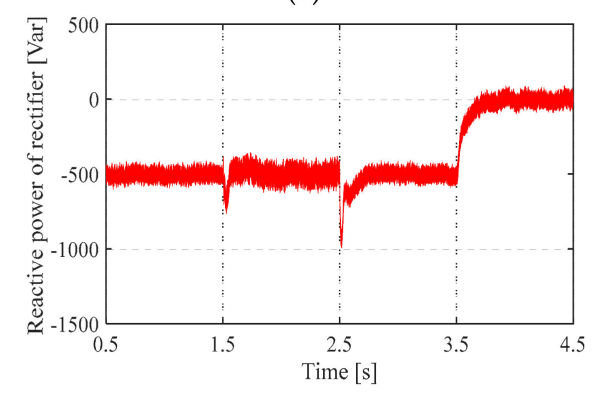

(c)

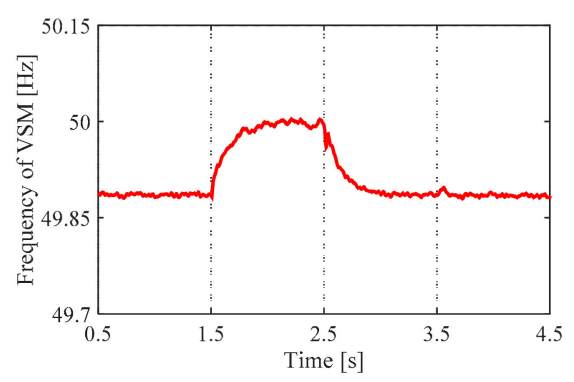

(b)

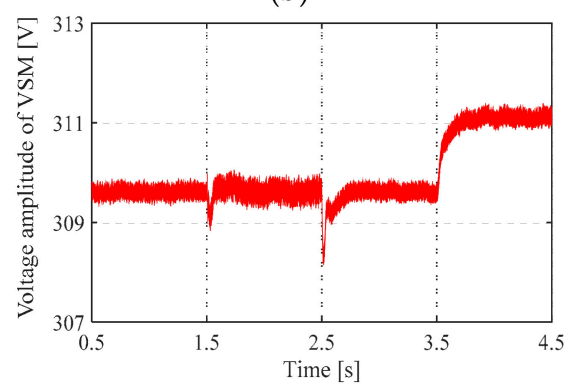

(d)

Figure 9. Primary regulation of VSM (a) Active power of the rectifier; (b) Frequency of VSM; (c) Reactive power of the rectifier; (d) Voltage amplitude of VSM.

\subsubsection{Comparison of Control Schemes}

The superiority of the proposed VSM-based charging system is confirmed by comparing with the traditional control. Most noteworthy, the traditional control $[19,20]$ means that the charging system does not possess the power regulation capabilities consistent with SM and only implements the charging function. The parameters of the VSM and grid are set in Table 2.

Table 2. Control parameters of the VSM and grid.

\begin{tabular}{llc}
\hline & \multicolumn{1}{c}{ Parameters } & Values \\
\hline & The charging power reference of the power battery I, $P_{\text {bat }}{ }^{*}$ & $150 U_{\text {bat }}$ \\
The reactive power reference of the rectifier, $Q^{*}$ & 0 Var \\
& The active droop coefficient of the VSM, $D_{\mathrm{p}}$ & 0.00009 \\
The reactive droop coefficient of the VSM, $D_{\mathrm{q}}$ & 0.003 \\
TSM control parameters & 0.1 \\
& The virtual Inertia of the VSM, $J$ & 20 \\
\hline & The active power reference of the grid, $P_{\mathrm{e}}^{*}$ & $200 \times 10^{3} \mathrm{~W}$ \\
& The reactive power reference of the grid, $Q_{\mathrm{e}}$ & $0 \mathrm{Var}$ \\
Grid control parameters & The active droop coefficient of the grid, $D_{\mathrm{pg}}$ & 0.00002 \\
& The reactive droop coefficient of the grid, $D_{\mathrm{qg}}$ & 0.003 \\
& The virtual Inertia of the grid, $J_{\mathrm{g}}$ & 0.01 \\
\hline
\end{tabular}

The proposed control and traditional control are applied to the off-board charger I, respectively. The variations of the two control methods on the frequency and voltage of the grid are contrasted when the power battery II joins in and drop out of services through off-board charger II and the reactive power of the AC interface fluctuates. To explain, for VSM-controlled off-board charger I, the rated capacity of the power battery I is $100 \mathrm{Ah}$, in order to make it work in a fast-charging mode, the charging 
current reference is set to 1.5 times rated capacity, i.e., $I_{\text {bat }}{ }^{*}=1.5 \mid$ Capacity $\mid=150$ A, so $P_{\text {bat }}{ }^{*}=\mathrm{I}_{\text {bat }}{ }^{*} \times$ $\mathrm{U}_{\text {bat }}=150 \mathrm{U}_{\text {bat }}$.

Based on the above situations and parameter settings, there are three simulation scenarios are considered:

(1) The simulation time is $4.5 \mathrm{~s}$. The grid quickly charged the power battery I with a charging current of 150 A through an off-board charger I before $1.5 \mathrm{~s}$.

(2) Power battery II is connected to the grid through the off-board charger II at $1.5 \mathrm{~s}$, but the battery II exits operation at $2.5 \mathrm{~s}$. In this time range, the consumed active power of the off-board charger II is $60 \mathrm{~kW}$.

(3) $2 \mathrm{kVar}$ reactive load at the AC interface is connected to the grid at $3.5 \mathrm{~s}$.

The simulation results are given in Figure 10, where the red line indicates the traditional control (Denoted by $x_{1}, x=\mathrm{a}, \mathrm{b}, \mathrm{c}, \ldots, \mathrm{h}$ ) and the blue line represents the proposed control (Denoted by $x_{2}$, $x=\mathrm{a}, \mathrm{b}, \mathrm{c}, \ldots, \mathrm{h})$.

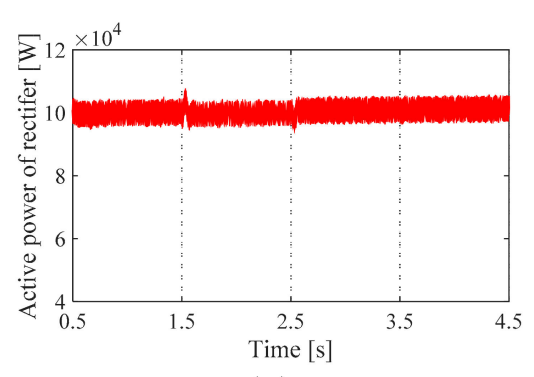

$(\mathbf{a})$

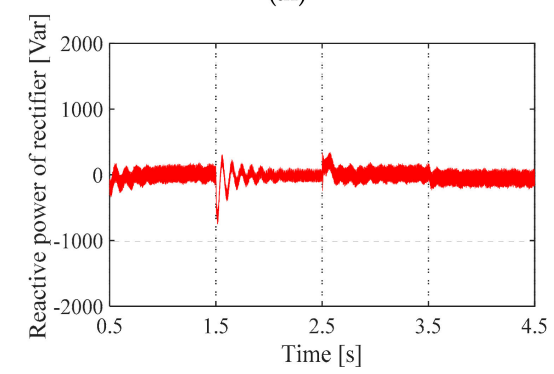

(b1)

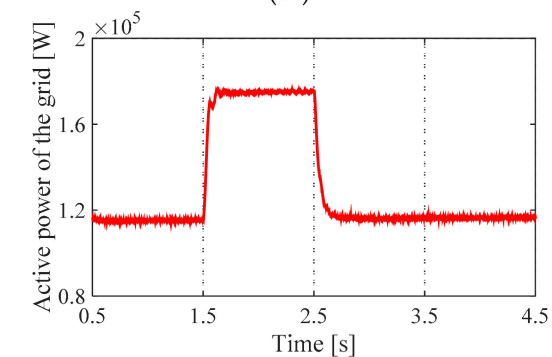

(c1)

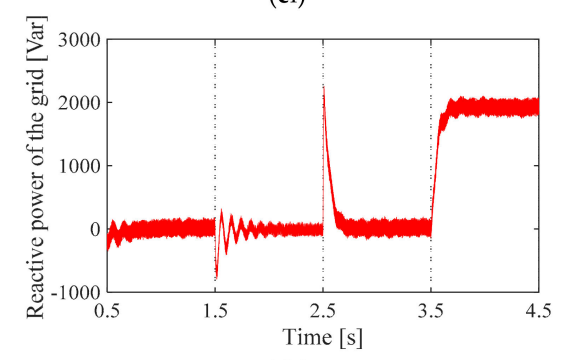

(d)

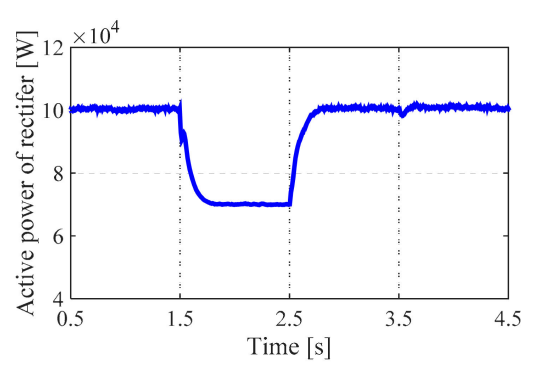

$(\mathbf{a})$

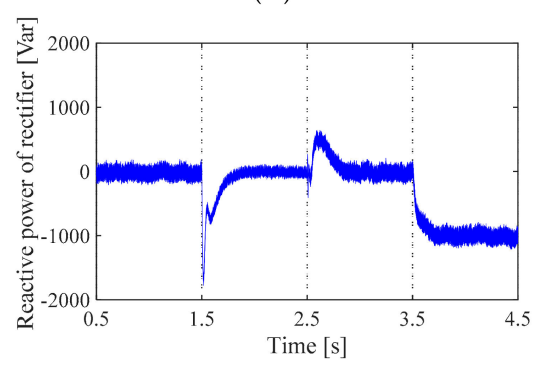

(b2)

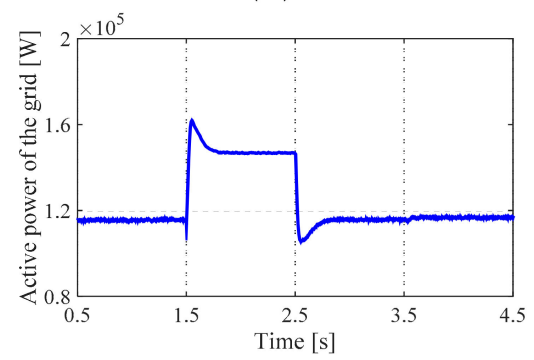

(c2)

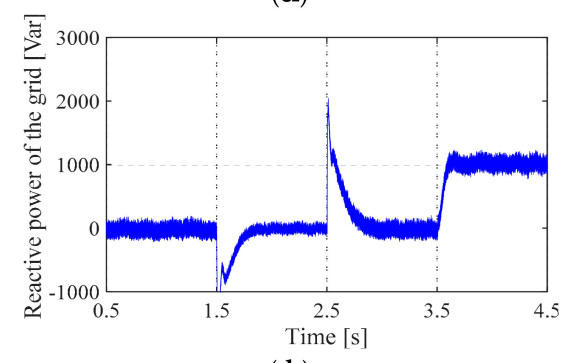

(d2)

Figure 10. Cont. 


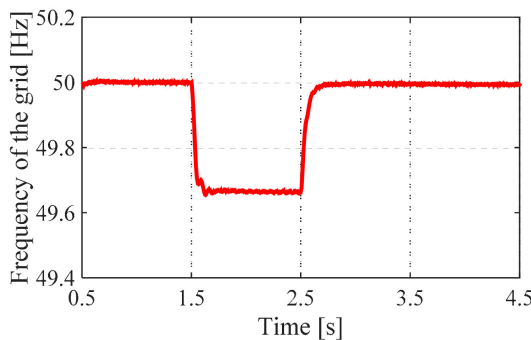

(e1)

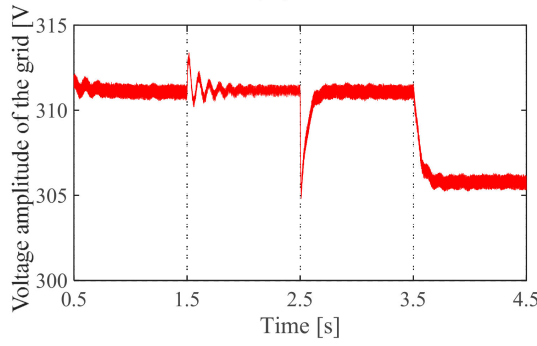

$\left(\mathbf{f}_{1}\right)$

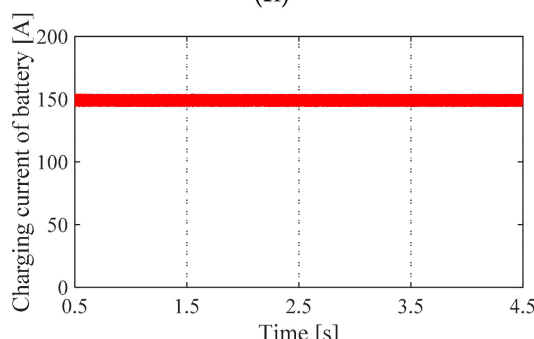

$\left(g_{1}\right)$

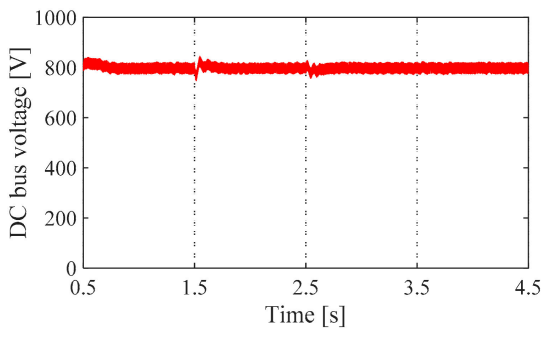

(h1)

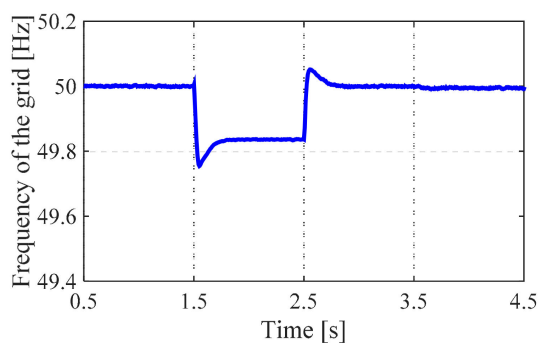

$\left(\mathbf{e}_{2}\right)$

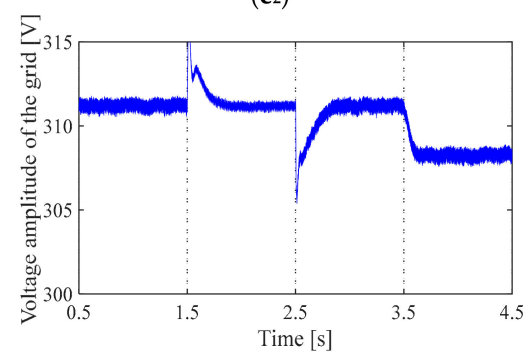

$\left(\mathbf{f}_{2}\right)$

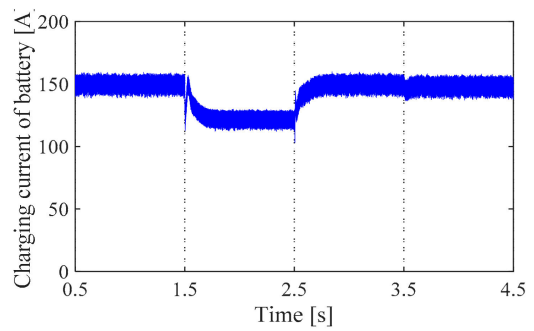

$\left(g_{2}\right)$

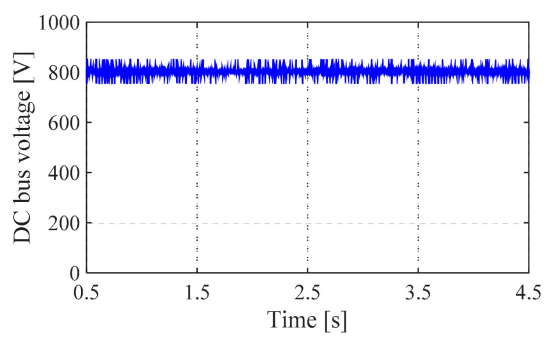

$\left(\mathbf{h}_{2}\right)$

Figure 10. Dynamic response waveforms of the grid and off-board charger I $\left(\mathbf{a}_{1}, \mathbf{a}_{2}\right)$ Active power of the rectifier; $\left(\mathbf{b}_{1}, \mathbf{b}_{\mathbf{2}}\right)$ Reactive power of the rectifier; $\left(\mathbf{c}_{\mathbf{1}}, \mathbf{c}_{\mathbf{2}}\right)$ Active power of the grid; $\left(\mathbf{d}_{\mathbf{1}}, \mathbf{d}_{\mathbf{2}}\right)$ Reactive power of the grid; $\left(\mathbf{e}_{\mathbf{1}}, \mathbf{e}_{\mathbf{2}}\right)$ Frequency of the grid; $\left(\mathbf{f}_{\mathbf{1}}, \mathbf{f}_{\mathbf{2}}\right)$ Voltage amplitude of the grid; $\left(\mathbf{g}_{1}, \mathbf{g}_{2}\right)$ Charging current of the power battery I; $\left(\mathbf{h}_{1}, \mathbf{h}_{\mathbf{2}}\right)$ DC bus voltage.

In the initial state, the grid rapidly charges the power battery I with $150 \mathrm{~A}$ charging current by the off-board charger I. When the power battery II is connected to the grid at $1.5 \mathrm{~s}$ and the reactive load is increased at $3.5 \mathrm{~s}$, for traditional control, Figure $10 \mathrm{a}_{1}, \mathrm{~b}_{1}$ show that the off-board charger I system does not partake in the active and reactive power regulation no matter how the loads change. In this case, the whole variations of power are entirely borne by the grid. As a result, the active power sent by the grid increases from $115 \mathrm{~kW}$ to $175 \mathrm{~kW}$ (as shown in Figure 10c 1 ), which results in the decrease of $0.32 \mathrm{~Hz}$ in grid frequency (as indicated from Figure $10 \mathrm{e}_{1}$ ). Furthermore, From Figure $10 \mathrm{~d}_{1}, \mathrm{f}_{1}$, after $3.5 \mathrm{~s}$, the reactive power emitted by grid increases from 0 Var to 2000 Var, which causes the voltage amplitude to drop from $311.159 \mathrm{~V}$ to $306 \mathrm{~V}$.

In contrast, for proposed control, the off-board charger I and the grid share the active and reactive power in a 1:1 ratio. Between 1.5 and $2.5 \mathrm{~s}$, it can be observed from Figure $10 \mathrm{a}_{2}, \mathrm{c}_{2}$ that the active power of the rectifier reduces from $100 \mathrm{~kW}$ to $75 \mathrm{~kW}$, and the power transmitted from the grid increases from $115 \mathrm{~kW}$ to $145 \mathrm{~kW}$. The sum of these two adjustments equals the consumed active power $60 \mathrm{~kW}$ of the 
off-board charger II. Compared with traditional control, the grid frequency only declines to $0.17 \mathrm{~Hz}$ in Figure $10 \mathrm{e}_{2}$. In addition, aiming at the access of $2 \mathrm{kVar}$ reactive load at $3.5 \mathrm{~s}$, Figure $10 \mathrm{~b}_{2}, \mathrm{~d}_{2}$ display that the rectifier reduces the reactive absorption of $1 \mathrm{kVar}$ and the grid generates $1 \mathrm{kVar}$ of reactive power. According to reactive droop coefficient, the voltage amplitude of the grid is a $3.15 \mathrm{~V}$ declines in Figure $10 \mathrm{f}_{2}$, whose drop degree is less than traditional control. Since VSM-controlled off-board charger I is involved in the regulation of the frequency and voltage, the charging current of the power battery I is lowered in Figure $10 \mathrm{~g}_{2}$ during the access period of the power battery II. However, the charging current remains constant at $150 \mathrm{~A}$ in the traditional control of Figure $10 \mathrm{~g}_{1}$. Besides, it can be observed in Figure $10 \mathrm{~h}_{2}$ that the post-stage closed-loop control can stabilize the DC bus voltage at a reference value of $800 \mathrm{~V}$.

\section{Conclusions}

This paper has presented a novel VSM-controlled scheme applied to the fast charging of the off-board charger. Control strategies of the off-board charger control and synchronous grid model are designed respectively, and the above strategies are verified by simulation. The investigated VSM not only provides ancillary services like participation in primary frequency control, reactive power regulation, and inertia and damping support for the grid, but also can be capable of achieving fast charging of the electric vehicles. Meanwhile, double closed-loop control improves the voltage stability of the DC interface. The designed synchronous grid model can simulate the actual distribution network characteristics accurately. The proposed novel-VSM control strategy can effectively enhance the quality of the frequency and voltage in the distribution network, especially in the nearby of the electric vehicles fast charging stations.

Author Contributions: X.Y. proposed the research direction and the VSM control method. J.L. completed the VSM control method. X.Y. proposed the synchronous grid model. J.L. established the mathematical model of the synchronous model. X.Y., J.L., B.Z., Z.J., Y.T., H.Z. and Z.L. performed the verification and analyzed the results. J.L. wrote the paper.

Acknowledgments: This paper was supported by the National Electric Net Ltd. (SGTYHT/16-JS-19); National Natural Science Fundings of Hebei (E2018502134); State Grid Corporation of Science and Technology Project (PD71-17-008); Liaoning Power Grid Corporation's 2018 Science and Technology Project “Research on the Reactive Power and Voltage Optimization Strategy and Evaluation Index Considering Source and Load Fluctuation Characteristics".

Conflicts of Interest: The authors declare no conflict of interest.

\section{References}

1. Van Roy, J.; Leemput, N.; Geth, F.; Buscher, J.; Salenbien, R.; Driesen, J. Electric vehicle charging in an office building microgrid with distributed energy resources. IEEE Trans. Sustain. Energy. 2014, 5, 1389-1396. [CrossRef]

2. Soares, F.J.; Rua, D.; Gouveia, C.; Tavares, B.D.; Coelho, A.M.; Lopes, J.A.P. Electric vehicles charging: Management and control strategies. IEEE Ves. Technol. Mag. 2018, 13, 130-139. [CrossRef]

3. Seljeseth, H.; Taxt, H.; Solvang, T. Measurements of network impact from electric vehicles during slow and fast charging. In Proceedings of the 22nd International Conference and Exhibition on Electricity Distribution (CIRED 2013), Stockholm, Sweden, 10-13 June 2013; pp. 1-4.

4. Sun, B.; Dragičević, T.; Freijedo, F.D.; Vasquez, J.C.; Guerrero, J.M. A control algorithm for electric vehicle fast charging stations equipped with flywheel energy storage systems. IEEE Trans. Power Electron. 2016, 31, 6674-6685. [CrossRef]

5. Shi, C.; Tang, Y.; Khaligh, A. A single-phase integrated onboard battery charger using propulsion system for plug-in electric vehicles. IEEE Trans. Veh. Technol. 2017, 66, 10899-10910. [CrossRef]

6. Shi, R.; Semsar, S.; Lehn, W.P. Constant current fast charging of electric vehicles via a DC grid using a dual-inverter drive. IEEE Trans. Ind. Electron. 2017, 64, 6940-6949. [CrossRef]

7. Badawy, M.O.; Sozer, Y. Power flow management of a grid tied PV-battery system for electric vehicles charging. IEEE Trans. Ind. Appl. 2017, 53, 1347-1357. [CrossRef] 
8. Nour, M.; Ramadan, H.; Ali, A.; Farkas, C. Impacts of plug-in electric vehicles charging on low voltage distribution network. In Proceedings of the 2018 International Conference on Innovative Trends in Computer Engineering (ITCE), Aswan, Egypt, 19-21 February 2018; pp. 357-362.

9. Gray, M.K.; Morsi, W.G. Power quality assessment in distribution systems embedded with plug-in hybrid and battery electric vehicles. IEEE Trans. Power Syst. 2015, 30, 663-671. [CrossRef]

10. Zhou, N.; Wang, J.; Wang, Q.; Wei, N. Measurement-based harmonic modeling of an electric vehicle charging station using a three-phase uncontrolled rectifier. IEEE Trans. Smart Grid. 2015, 6, 1332-1340. [CrossRef]

11. Suul, J.A.; D'Arco, S.; Guidi, G. A single-phase virtual synchronous machine for providing vehicle-to-grid services from electric vehicle battery chargers. In Proceedings of the International Electric Vehicle Technology Conference \& Automotive Power Electronics-EV-TeC \& APE, Yokohama, Japan, 22-24 May 2014; p. 7.

12. Suul, J.A.; D'Arco, S.; Guidi, G. Virtual synchronous machine-based control of a single-phase bi-directional battery charger for providing vehicle-to-grid services. IEEE Trans. Ind. Appl. 2016, 52, 3234-3244. [CrossRef]

13. Liu, Q.H.; Lu, S.J. Charging and discharging control strategy based on virtual synchronous machine for electrical vehicles participating in frequency modulation of Microgrid. Autom. Elect Power Syst 2018, accepted.

14. Jiang, W.; Lv, Z.; Zhong, Q.; Zeng, B.; Li, G. Virtual synchronous motor based control scheme of electric vehicle charger. In Proceedings of the 2014 International Conference on Power System Technology, Chengdu, China, 20-22 October 2014; pp. 2686-2692.

15. Guerrero, J.M.; Vasquez, J.C.; Matas, J.; de Vicuna, L.G.; Castilla, M. Hierarchical control of droop-controlled $\mathrm{AC}$ and DC microgrids-A general approach toward standardization. IEEE Trans. Ind. Electron. 2011, 58, 158-172. [CrossRef]

16. Rocabert, J.; Luna, A.; Blaabjerg, F.; Rodríguez, P. Control of power converters in AC microgrids. IEEE Trans. Power Electro. 2012, 27, 4734-4749. [CrossRef]

17. Shen, Y.; Zhao, W.; Chen, Z.; Cai, C. Full-bridge LLC resonant converter with series-parallel connected transformers for electric vehicle on-board charger. IEEE Access 2018, 6, 13490-13500. [CrossRef]

18. Vu, H.N.; Choi, W. A novel dual full-bridge LLC resonant converter for CC and CV charges of batteries for electric vehicles. IEEE Trans. Ind. Electron. 2018, 65, 2212-2225. [CrossRef]

19. Varghese, A.S.; Thomas, P.; Varghese, S. An efficient voltage control strategy for fast charging of plug-in electric vehicle. In Proceedings of the 2017 Innovations in Power and Advanced Computing Technologies (i-PACT), Vellore, India, 21-22 April 2017; pp. 1-4.

20. Zheng, Z.; Wang, K.; Xu, L.; Li, Y. A hybrid cascaded multilevel converter for battery energy management applied in electric vehicles. IEEE Trans. Power Electron. 2014, 29, 3537-3546. [CrossRef] 